\title{
eSport: Construct Specifications and Implications for Sport Management
}

\author{
George B. Cunningham \\ Texas A\&M University \\ Sheranne Fairley \\ University of Queensland \\ Lesley Ferkins \\ Auckland University Technology \\ Shannon Kerwin \\ Brock University \\ Daniel Lock \\ Bournemouth University \\ Sally Shaw \\ University of Otago \\ Pamela Wicker \\ German Sport University Cologne
}

\section{Author Notes}

Cunningham is with the Department of Health and Kinesiology, and the Women's and Gender Studies Program, at Texas A\&M University;

Fairley is with the Business School at The University of Queensland, Brisbane, Australia;

Ferkins is with the AUT Sports Performance Research Institute New Zealand, Auckland University of Technology

Wicker is with the Department of Sport Economics and Sport Management, German Sport University Cologne.

Kerwin is with the Department of Sport Management in the Faculty of Applied Health Sciences at Brock University, Canada.

Lock is with the Department of Sport and Physical Activity, Bournemouth University, United Kingdom.

Shaw is with the School of Physical Education, Sport and Exercise Sciences, University of Otago, Dunedin, New Zealand.

Address all correspondence to George B. Cunningham, gbcunningham@tamu.edu. 


\begin{abstract}
The purpose of this article is to add to the conceptual discussion on eSport, analyze the role of eSport within sport management, and suggest avenues for future eSport research. The authors suggest that debates surround the degree to which eSport represents formal sport, and disagreements likely stem from conceptualizations of sport and context. Irrespective of one's notion of eSport as formal sport, the authors suggest the topic has a place in sport management scholarship and discourse. Such a position is consistent with the broad view of sport adopted by Sport Management Review, the perspective that eSport represents a form of sportification, and the association among eSport and various outcomes, including physical and psychological health, social well-being, sport consumption outcomes, and diversity and inclusion. Finally, the authors conclude that eSport scholarship can advance through the study of its governance, marketing, and management as well as by theorizing about eSport.
\end{abstract}

Keywords: eSport; fantasy sport; physical activity; sportification 


\section{Introduction}

eSport represents tournament level, interactive video games, described by British eSports as "the top level of video gaming in terms of skill and professionalization" (What are eSports?, 2016). Their popularity is evidenced by the amount of participants, spectators, and media coverage; as well as organizers considering eSport for inclusion in major sport competitions. According to Newzoo, a company that specializes in offering market data related to digital media and related activities, there were 191 million eSport enthusiasts around the world in 2017 (eSports, 2017). These figures are up considerably from 2016 (148 million enthusiasts; Rapaport, 2017). Industry revenues have followed suit, with US\$493 million generated in 2016 and US\$660 million in 2017. Spectator attendance for eSport is equally impressive. The tournaments have sold out large venues, such as Key Arena in Seattle and Madison Square Garden in New York City (Rapaport, 2017). But, even more impressive is the online spectatorship; in fact, the "League of Legends" World Finals drew 12 million more fans than the National Basketball Association (NBA) finals held at the same time (Clavio, 2017). The growth of eSport has not been lost on popular press outlets, where the likes of Forbes, ESPN, Sports Illustrated, and the Guardian, among others, all cover aspects of the events. Finally, the rise of eSport is perhaps best illustrated by news in 2017 that it would be a medal event in the 2022 Asian Games (Graham, 2017).

The rise of eSport has not been lost on academics. At past Sport Management Review (SMR) editorial meetings, as part of broader discussions about the boundaries of sport management, board members have discussed and debated the role of eSport, whether the activity should be considered sport at all, and the implications for sport management as a discipline. When the topic was first broached, some members met the discussion with a healthy skepticism, 
perhaps thinking that it was a passing fad. As eSport grew, however, so too did attention dedicated to the topic - by sponsors, spectators, and academics.

The discussions ultimately resulted in the scholarly exchange presented in this issue of SMR. We asked experts in the field to consider two questions: (a) is eSport a sport; and (b) irrespective of the response to the first question, is eSport relevant for the sport management discipline? In this introductory article to the exchange, we, as the SMR editorial team, address these questions, too. In doing so, we seek to contribute to the emerging dialogue surrounding eSport and identify potential paths forward.

\section{Construct specification}

We first asked the authors to consider whether eSport was a sport. Though Funk, Pizzo, and Baker (2018) and Hallmann and Giel (2018) both spoke to the question, Heere (2018) was resistant to even address the idea. He argued: "To think that sport management scholars are in control of what should or should not be defined as sport, is an illusion" (p. XX). He further suggested that "it falls outside the purview of sport management scholars to decide what or what does not qualify as sport" (p. XX).

Although we appreciate Heere's (2018) perspective, there are several reasons to consider whether eSport is a sport. First, Sport Management Review is a "multidisciplinary journal concerned with the management, marketing, and governance of sport at all levels and in all its manifestations - whether as an entertainment, a recreation, or an occupation." As the statement suggests, sport is the focus of the journal; thus, considering the boundaries of sport, or of activities that influence its management, marketing, or governance, not only is of interest to scholars, but also a duty of the editorial board. Second, consideration of what constitutes sport has considerable economic and financial ramifications. As Hallmann and Giel (2018) note, some 
countries provide subsidies for sport as a means of promoting sport involvement (see also Breuer, 2011; Miles, 2017). Thus, if eSport was considered a sport, a national federation could receive government funding. Finally, construct definition and specification is an activity in which academicians engage. Part of the theory development process, for example, is defining constructs and how they relate to other constructs (Bacharach, 1989). As theory and theory building are fundamental to the development of an academic discipline (Cunningham, Fink, \& Doherty, 2016), engaging in scholarly discussions around constructs - in this case, what constitutes sport — is a core function of the academic enterprise.

In returning to the question at hand, we consider sport to represent (a) a physical activity, (b) requiring skill, (c) that is competitive in nature and (d) has a level of stability and (e) institutional organization (see also Rodgers, 1977; Suits, 2007). Past scholars who have reviewed the question have generally agreed that eSport requires skill, is competitive in nature, has a level of stability (e.g., coaches, sponsors, and large following), and has some level of institutionalization of rules, records, and other standards, though the latter point is somewhat debated, too (Funk et al., 2018; Hallmann \& Giel, 2018; Jenny, Manning, Keiper, \& Olrich, 2017; Keiper, Manning, Jenny, Olrich, \& Croft, 2017).

The notion of eSport as a physical activity is more contentious. Funk et al. present data related to fine motor skills and elevated physiological readings to suggest that eSport does have a physical component. Moreover, considering that some activities that are stereotypically not considered as overly physical, such as racecar driving or rifle shooting, are also considered sport, Funk et al.’s rationale is compelling. To their point, physiologists have provided empirical evidence of racecar drivers possessing similar cardiorespiratory capacity as athletes in basketball, football, or baseball (Jacobs, Olvey, Johnson, \& Cohn, 2002), and they have demonstrated 
physical activity ratios comparable to athletes in basketball or soccer (Beaune, Durand, \& Mariot, 2010). In light of these studies, such comparative research might be helpful for eSport in an effort to make a case for it to be considered a physical activity. That noted, exertion of fine motor skills does not necessarily equate to physical activity (Hallmann \& Giel, 2018). In fact, eSport competitors sit during practice and competition, remaining sedentary for up to 15 hours a day (Hattenstone, 2017). Given the association between sedentary behavior and poor physical, psychological, and cognitive health (de Rezende, Lopes, Rey-López, Matsudo, \& do Carmo Luiz, 2014; Owen, Healy, Matthews, \& Dunstan, 2010), this potentially places eSport in a contestable position when considering its inclusions as a sport.

This positioning becomes increasingly complex when viewing classifications of sport from an international perspective. In Canada, for example, government funding from Sport Canada provides a tangible classification for what is sport and what is not. Specifically, national sport organizations are funded for the purpose of providing enhanced sport programming ranging from community sport clubs to high performance training centers. Within this context, eSport is not funded by the government, and thus could be argued that it is not considered a sport in Canada. In New Zealand (NZ), which shares many public funding similarities to Canada, sports can apply for government funding if they meet certain criteria, including the potential to win medals at international tournaments. The New Zealand eSports Federation Incorporated (NZESF) is the governing body for eSports in NZ. Among its objectives are to "advocate for the recognition of eSports as an indoor sport in NZ and inclusion in the Olympics;" "promote the social, health and educational benefits of eSports and video games for youth and the wider community;" and "promote a healthy and balanced lifestyle for eSports participants" (NZESF, 2016). In this context, it is highly possible that NZESF could apply for funding to compete, for 
example, at the Asian Games. In this context, eSports could, given NZEF's objectives, be defined as a sport. Therefore, the institutional structures surrounding sport funding and governance are also salient concerns when tackling the question of whether eSports should, or should not, be considered as sport.

As an alternative, Seo (2016) suggested that eSport involvement is a form of serious leisure. He drew from Stebbins' view of serious leisure as "the systematic pursuit of an amateur, hobbyist, or volunteer activity that participants find so substantial and interesting, in the typical case, they launch themselves on a career centered on acquiring and expressing its special skills, knowledge and experience" (p. 3). Note that Stebbins' definition does not require a physically active component. Seo interviewed professional eSport participants and found that they moved from participating in gaming as a casual activity to a serious occupational pursuit. At this point, eSports participation transitions from serious leisure into a profession. However, regardless of the level Seo noted the competitive nature of eSport, cultural norms in the eSport community, and dedication needed to excel. Seo did not, however, suggest that their involvement entailed a physical component.

The aforementioned discussion highlights the various debates and ambiguities surrounding eSport as a formal sport. We suggest that the equivocality largely stems from three factors: (a) the definition of sport from which one draws; (b) the degree to which the fine motor skills clearly observed in eSport are a form of physicality; and (c) context and whether national governing bodies designate the activity as a sport. In short, the debate continues.

\section{3 eSport, sport management, and Sport Management Review}

Irrespective of whether eSport is a sport, or even not yet a sport (Hallmann \& Giel, 2018), should it be a focus for sport management scholars? More germane to the discussion at 
hand, should we, as the editors of Sport Management Review, accept and publish articles on the topic? As evidenced by the scholarly forum in this issue, we obviously believe that eSport has a place in the sport management discourse, and there are many reasons for this.

First, from a journal perspective, we take a broad view of sport and consider research where authors specifically focus on sport. We also, however, review and publish scholarship where attention is on physical activities related to sport (e.g., fitness; García-Fernández et al., in press), sport for development and peace where activities can be cooperative rather than competitive in nature (Lyras \& Welty Peachey, 2011), factors that influence the purchase of active wear (Zhou et al., in press), fantasy sports (Karg \& McDonald, 2011; Yuksel, McDonald, Milne, \& Darmody, 2017), and running events (Inoue, Heffernan, Yamaguchi, \& Filo, in press), among others. The aforementioned list is illustrative of activities and events that are associated with sport and might ultimately influence the delivery of sport or sport products. One could easily make a similar argument for eSport. Sport organizations, such as the National Basketball Association, are affiliating with eSport and even sponsoring teams (Wolf, 2017). Philadelphia 76ers chief executive Scott O'Neil commented, "it's a good opportunity to reach younger fans in a different way and hopefully incorporate them into our fanbase and vice-versa" (in Wolf, 2017).

The argument outlined above (Wolf, 2017) is in line with the discussion of Newman (2014), Stewart (2014), and Zeigler (2007). The former two scholars opened much needed dialogue around the way in which we conceptualize and discuss sport management theory and practice. Newman stressed that the evolution of a market society has led to the commercialization of sport, where this argument may lend support to the notion that a marketfocused view of sport (e.g., eSport is useful to gain a larger fanbase) is good for some (i.e., organizations), but not the many (i.e., sedentary children and adults). Stewart responded to 
Newman's claim by highlighting the reality of today's sport system, and the need to critically review the connection between sport management, marketing, play, and fun to uncover the place that activities (such as eSport) have in the sport industry. This particular call by Stewart emphasizes Zeigler's claim that social concern (i.e., physical activity, health rates, psychological well-being) must be at the forefront as we tackle theory develop generally, and around emerging trends such as eSport, more specifically.

Second, in line with Heere (2018), eSport represents a form of sportification, where the term means:

To either: (a) view, organize or regulate a non-sport activity in such a way that it resembles a sport and allows a fair, pleasurable and safe environment for individuals to compete and cooperate, and compare their performance to each other, and future and past performances; or (b) add a sport component to an existing activity in order to make it more attractive to its audiences. (p. XX)

From this perspective, eSport is a manifestation of sportification, and sport management academics can and should consider the negative and positive impacts of eSport on the broader sport industry.

Third, and in the same vein as examining the impact of eSport, we see opportunities for examining the link between the rise of eSport and various outcomes. One outcome concerns the link between eSport and health. Recent research from Common Sense (2017) showed that mobile screen time usage for US children aged eight and under has increased 10-fold since 2011 (Howard, 2017). Today, children spend about 50 minutes a day on phones and over two hours overall in front of any screen. Screen time has a reliable association with increased adiposity and decreased exercise (Ballard, Gray, Reilly, \& Noggle, 2009). Others have noted the potential 
negative effects of extensive gaming on psychological outcomes, such as aggression, addictive behaviors, and depression (Anderson et al., 2010; Ferguson, 2013; Lemola et al., 2011). We also recognize, however, that the discussion is not one-sided, as some scholars have argued that gaming might provide physical, cognitive, motivational, emotional, and social benefits (Biddiss \& Irwin, 2010; Granic, Lobel, \& Engels, 2014). Thus, we see the opportunity for more research in the area to better understand the influence of eSport participation on individuals' physical and psychological health.

Related to the focus on eSport and health is the study of social outcomes related to eSport participation because existing research has found a positive effect of social relationships on measures of psychological health such as life satisfaction (Orlowski \& Wicker, 2015; Powdthavee, 2008). Previous research has documented that under specific conditions, including the cooperative nature of some sports and participants strongly identifying with a group, sport has the potential to increase social well-being, while also reducing loneliness and aggression (Pels \& Kleinert, 2016a, 2016b). Hence, it is possible that eSport enthusiasts are drawn to participate by social motives, similar to the camaraderie (Ruihley \& Hardin, 2011) and social interaction (Lee, Seo, \& Green, 2013) shared by fantasy sport participants, and the social interest evinced by video gamers (Cianfrone, Zhang, \& Ko, 2011). Pertinent follow-up research would examine whether and how participating in eSport can be associated with various social outcomes, such as social capital, social well-being, aggression, and loneliness. Research of this nature would help organizations such as the NZESF in its objective to assist eSport participants in developing balanced lifestyles.

Another germane focus for eSport researchers concerns its potential association with sport consumption. As mentioned, some executives of professional sport teams anticipate their 
sponsorship of an eSport team will result in an increase of their fan base (Wolf, 2017). Past researchers have also added credence to this argument. In a study tangentially related to eSport, Goldsmith and Walker (2015) examined whether fantasy sport participation could move nonfans to being fans. Results of their multistage study supported this hypothesis: people who considered themselves non-fans of NASCAR moved to being involved fans after participating in fantasy sports. It is possible a similar pattern would emerge with eSport players and consumers. In addition, the contributors to the scholarly exchange all discussed the relationship among eSport, diversity, and inclusion. Men (Nelson \& Rogers, 2003) have historically dominated computer science and other academic fields associated with gaming. The lack of diversity has carried over to eSport, as well. Keiper et al. (2017) estimated that less than a third of all eSport fans and participants were women. The events frequently feature abusive language as well as the hypersexualization of women (Consalvo, 2012; Krischer, 2016). Recognizing the pervasiveness of exclusionary cultures, Funk et al. (2018) noted: "eSport remains a highly gendered environment, and identifying barriers to competition and spectatorship is a strength of sport management research that can be leveraged by eSport” (p. XX). We echo these sentiments.

\section{Moving forward with eSport research}

Finally, we see a number of opportunities for research in the governance, marketing, and management of eSport. From a governance perspective, Funk et al. (2018) offered several points to consider, including the emergence of colleges and universities offering scholarships to eSport participants (see also Schaeperkoetter et al., 2017), legal issues with eSport as sport, labor issues, and ownership issues. Hallmann and Giel (2018) offered additional considerations, questioning not if, but when, governmental bodies will consider eSport a sport. In addition to these points, we note that the 2022 Asian Games will include eSport in the program. Will other sport governing 
bodies follow suit, and if so, does eSport's inclusion come at the expense of more established, traditional sport forms? What are the long-term ramifications of these decisions for countries and their sport development systems?

In terms of marketing, it is clear some professional sport leagues seek to entice new fans through their eSport activation (Wolf, 2017). What is less clear is how this objective will be achieved. Though some eSport activities involve sport video games, the most popular ones do not (Clavio, 2017). How can eSport participants, even the few who participate in sport related games, move from people engaging in serious leisure to fans of the physical sports themselves? In addition, given the large fan base at the events and online (Clavio, 2017; Rapaport, 2017), do eSport events offer sponsorship opportunities that are otherwise not evident for traditional sport events? These are questions worth pursuing.

From a management perspective, there are potential opportunities to use eSport as a way of engaging people in sport and physical activity who would not be active otherwise. Some scholars have recognized the use of music (Cohen \& Ballouli, 2017) and other technologies (Garney et al., 2017) as a means of attracting people to be more active. These strategies are particularly effective at engaging otherwise marginalized populations. Can eSport play a similar role (Heere, 2018)? In addition, even though most eSport competitions and modes of gaming involve sedentary behaviors, this may not be the case for all as eSport evolves. Already, some researchers have observed that active gaming, which requires participants to be physically active while playing the video game, provides physical benefits, for youth and elderly alike (Biddiss \& Irwin, 2010; Larsen, Schou, Lund, \& Langberg, 2013). Indeed, research at the University of Otago is underway at the time of writing to examine whether and how gaming can be developed into an educational tool for young children to copy and learn physical activities. We see these 
findings as an opportunity for eSport federations and managers, as they can expand the eSport offerings to include more physically active forms of participation.

Finally, and perhaps most importantly for sport management scholars, we see a need for theorizing about eSport. Much of the work to date is atheoretical in nature, and as such, there is no firm foundation for building research questions or hypotheses, designing methods, analyzing data, or drawing conclusions. Theory provides such a foundation, it is "the bedrock upon which good scholarship rests" (Cunningham, 2013, p. 2) and "the currency of our scholarly realm" (Corley \& Gioia, 2011, p. 2). Importantly, theory also aids in practice (Doherty, 2013; Irwin \& Ryan, 2013), or, in this case, the effective delivery of eSport. The questions we and the other contributing authors have posed all deserve theoretical attention, as doing so will move us beyond conjecture about eSport and into the position of identifying and explaining why, how, when, and under what conditions various eSport phenomena might take place.

\section{Conclusions}

In this introduction to the scholarly exchange, the Editorial Team of $S M R$ has responded to two pertinent questions: (a) is eSport a sport; and (b) irrespective of the response to the first question, is eSport relevant for the sport management discipline? As the other contributors to this exchange discuss, the responses to these questions are not straightforward. eSports do satisfy four of the five characteristics of sport (Rogers, 1977). However, despite arguments to the contrary, the degree to which eSport involves physical activity is contestable. In the end, the demarcation of eSport as a sport is likely to depend on the conceptualization used and the specific context. Regardless of this observation, eSport is becoming increasingly interwoven into the fabric of sport organizations (e.g., sponsorship) in attempts to broaden market appeal. What does matter is that eSport is progressively featured in the sporting landscape and that eSport, and 
its descendants, will continue to grow for as long as there are developments in gaming technologies. Like studies of the fitness industry, sport for development and peace, active wear purchases, fantasy sports, and event participation - eSport presents the Sport Management academy with a series of problems and questions that, while not certainly of a sporting nature, have direct relevance for the management of sport in the future. 


\section{References}

Anderson, C. A., Shibuya, A., Ihori, N., Swing, E. L., Bushman, B. J., Sakamoto, A., \& Saleem, M. (2010). Violent video game effects on aggression, empathy, and prosocial behavior in Eastern and Western countries: A meta-analytic review. Psychological Bulletin, 136, $151-173$.

Bacharach, S. B. (1989). Organizational theories: Some criteria for evaluation. Academy of Management Review, 14, 496-515.

Ballard, M., Gray, M., Reilly, J., \& Noggle, M. (2009). Correlates of video game screen time among males: body mass, physical activity, and other media use. Eating Behaviors, 10(3), 161-167.

Beaune, B., Durand, S., \& Mariot, J. (2010). Open-wheel race car driving: energy costs for pilots. Journal of Strength and Conditioning Research, 24(11), 2927-2932.

Biddiss, E., \& Irwin, J. (2010). Active video games to promote physical activity in children and youth: A systematic review. Archives of Pediatrics \& Adolescent Medicine, 164(7), 664672.

Breuer, M. (2011). E-Sport: eine markt- und ordnungsökonomische Analyse. Boizenberg: Hulsbusch.

Consalvo, M. (2012). Confronting toxic gamer culture: A challenge for feminist game studies scholars. Ada: A Journal of Gender, New Media, and Technology. http://dx.doi.org/10.7264/N33X84KH.

Cianfrone, B. A., Zhang, J. J., \& Ko, Y. J. (2011). Dimension of motivation associated with playing sport video games. Modification and extension of the Sport Video Game 
Motivation Scale. Sport, Business, and Management: An International Journal, 1(2), 172-189.

Clavio, G. (2017, May). Are esports the next major league sport? The Conversation. Retrieved online from: https://theconversation.com/are-esports-the-next-major-league-sport-74008.

Corley, K. G., \& Gioia, D. A. (2011). Building theory about theory building: what constitutes a theoretical contribution? Academy of Management Review, 36(1), 12-32.

Cunningham, G. B. (2013). Theory and theory development in sport management. Sport Management Review, 16, 1-4.

Cunningham, G. B., Fink, J. S., \& Doherty, A. (2016). Developing theory in sport management. In G. B. Cunningham, J. S. Fink, \& A Doherty (Eds.), Routledge handbook of theory in sport management (pp. 3-8). New York, NY: Routledge.

de Rezende, L. F. M., Lopes, M. R., Rey-López, J. P., Matsudo, V. K. R., \& do Carmo Luiz, O. (2014). Sedentary behavior and health outcomes: an overview of systematic reviews. PloS One, 9(8), e105620.

Doherty, A. (2013). Investing in sport management: The value of good theory. Sport Management Review, 16(1), 5-11.

Esports. (2017). Newzoo. Retrieved online from https://newzoo.com/insights/markets/esports/.

Ferguson, C. J. (2013). Violent video games and the Supreme Court. American Psychologist, 68, $57-74$

Funk, D. C., Pizzo, A. D., \& Baker, B. J. (2018). eSport management: Embracing eSport education and research opportunities. Sport Management Review, 21, XX-XX.

García-Fernández, J., Gálvez-Ruiz, P., Fernández-Gavira, J., Vélex-Colón, L., Pitts, B., \& Bernal-García, A. (in press). The effects of service convenience and perceived quality on 
perceived value, satisfaction and loyalty in low-cost fitness centers. Sport Management Review.

Garney, W. R., Wendel, M., McLeroy, K., Alaniz, A., Cunningham, G., Castle, B., Ingram, M., \& Burdine, J. (2017). Using community health development to increase community capacity: A multiple case study. Family and Community Health, 40, 18-23.

Goldsmith, A. L., \& Walker, M. (2015). The NASCAR experience: Examining the influence of fantasy sport participation on 'non-fans'. Sport Management Review, 18(2), 231-243.

Graham, B. A. (2017, April). eSports to be a medal event at 2022 Asian Games. The Guardian. Retrieved online from: https://www.theguardian.com/sport/2017/apr/18/esports-to-bemedal-sport-at-2022-asian-games.

Granic, I., Lobel, A. M., \& Engels, R. C. M. E. (2014). The benefits of playing video games. American Psychologist, 69, 66-78.

Hallmann, K., \& Giel, T. (2018). eSports - Competitive sports or recreational activity? Sport Management Review, 21, XX-XX.

Hattenstone, S. (2017, June). The rise of eSports: Are addiction and corruption the price of its success? The Guardian. Retrieved online from https://www.theguardian.com/sport/2017/jun/16/top-addiction-young-people-gamingesports.

Heere, B. (2018). Embracing the sportification of society: Defining e-sports through a polymorphic view of sport. Sport Management Review, 21, XX-XX.

Howard, J. (2017, October). Kids under 9 spend more than 2 hours a day on screens, report shows. CNN. Retrieved online from: http://www.cnn.com/2017/10/19/health/childrensmartphone-tablet-use-report/index.html. 
Inoue, Y., Heffernan, C., Yamaguchi, T., \& Filo, K. (in press). Social and charitable impacts of a charity-affiliated sport event: A mixed methods study. Sport Management Review.

Irwin, R. L., \& Ryan, T. D. (2013). Get real: Using engagement with practice to advance theory transfer and production. Sport Management Review, 16(1), 12-16.

Jacobs, P., L., Olvey, S. E., Johnson, B. M., \& Cohn, K. A. (2002). Physiological responses to high-speed, open-wheel racecar driving. Medicine \& Science in Sports \& Exercise, 34(12), 2085-2090.

Jenny, S. E., Manning, R. D., Keiper, M. C., \& Olrich, T. W. (2017). Virtual(ly) athletes: Where eSports fit within the definition of "sport". Quest, 69, 1-18.

Karg, A. J., \& McDonald, H. (2011). Fantasy sport participation as a complement to traditional sport consumption. Sport Management Review, 14(4), 327-346.

Keiper, M. C., Manning, D. C., Jenny, S., Olrich, T., \& Croft, C. (2017). No reason to LoL at LoL: The addition of esports to intercollegiate athletic departments. Journal for the Study of Sports and Athletes in Education, 11, 143-160.

Krischer, H. (2016). Closing the gender gap: one e-battle at a time. New York Times. Retrieved online from: https://www.nytimes.com/2016/06/26/fashion/league-of-legends-womenvideo-games.html.

Larsen, L. H., Schou, L., Lund, H. H., \& Langberg, H. (2013). The physical effect of exergames in healthy elderly — a systematic review. Games for Health: Research, Development, and Clinical Applications, 2(4), 205-212.

Lee, S., Seo, W. J., \& Green, B. C. (2013). Understanding why people play fantasy sport: development of the Fantasy Sport Motivation Inventory (FanSMI). European Sport Management Quarterly, 13(2), 166-199. 
Lemola, S., Brand, S., Vogler, N., Perkinson-Gloor, N., Allemand, M., \& Grob, A. (2011). Habitual computer game playing at night is related to depressive symptoms. Personality and Individual Differences, 51, 117- 122.

Nelson, D. J., \& Rogers, D. C. (2003). A national analysis of diversity in science and engineering faculties at research universities. National Organization for Women.

New Zealand eSports Federation (2016). About us. Retrieved from http://www.esf.nz/?page_id=12. Accessed 26 October.

Orlowski, J., \& Wicker, P. (2015). The monetary value of social capital. Journal of Behavioral and Experimental Economics, 57, 26-36.

Owen, N., Healy, G. N., Matthews, C. E., \& Dunstan, D. W. (2010). Too much sitting: The population-health science of sedentary behavior. Exercise and Sport Science Review, 38(3), 105-113.

Pels, F., \& Kleinert, J. (2016a). Enhancing mental health: Effects of exercise on social wellbeing and social ill-being. In S. Schneider (Ed.), Exercise in Space. A holistic approach for the benefit of human health on Earth (pp. 63-90). Cham: Springer.

Pels, F., \& Kleinert, J. (2016b). Loneliness and physical activity: A systematic review. International Review of Sport and Exercise Psychology, 9(1), 231-260.

Powdthavee, N. (2008). Putting a price tag on friends, relatives, and neighbors: Using surveys of life satisfaction to value social relationships. Journal of Socio-Economics, 37(4), 14591480.

Rapaport, D. (2017, February). What to expect from the booming esports industry in 2017. Sports Illustrated. Accessed online from: https://www.si.com/techmedia/2017/02/09/esports-industry-expectations-billion-dollar. 
Rodgers, B. (1977). Rationalizing sport policies: Sport in its social context. International comparisons. Strabourg: Council of Europe.

Ruihley, B. J., \& Hardin, R. L. (2011). Behind touchdowns, homeruns, and three-pointers: an examination of fantasy sport participation motivation. International Journal of Sport Management and Marketing, 10(3/4), 232-256.

Schaeperkoetter, C. C., Oja, B., Mays, J., Krueger, K., Hyland, S. T., Christian, R., Wilkerson, Z., \& Bass, J. R. (2017). The "new” student-athlete: An exploratory examination of scholarship eSports players. Journal of Intercollegiate Sport, 10, 1-21.

Seo, Y. (2016). Professionalized consumption and identity transformations in the field of eSports. Journal of Business Research, 69, 264-272.

Stebbins, R. A. (1992). Amateurs, professionals, and serious leisure. Montreal, Canada: McGillQueen's University Press.

Suits, B. (2007). The element of sport. In W. Morgan (Ed.), Ethics in sport (pp. 9-19). Champaign, IL; Human Kinetics.

What are eSports? An overview for non-fans (2016). British eSports Association. Available from http://www.britishesports.org/106/news/what-are-esports-an-overview-for-nonfans.html. Retrieved 16 October.

Wolf, J. (2017, May). NBA announces 17 teams will participate in NBA 2K League. ESPN. Retrieved online from: http://www.espn.com/esports/story//id/19305330/nbaannounces-17-teams-participate-nba-2k-esports-league.

Yuksel, M., McDonald, M. A., Milne, G. R., \& Darmody, A. (2017). The paradoxical relationship between fantasy football and NFL consumption: Conflict development and consumer coping mechanisms. Sport Management Review, 20(2), 198-210. 
Zhou, X., Hanlon, C., Robertson, J., Spaaij, R., Westerbeek, H., Hossack, A., \& Funk, D. C. (in press). Dress for fit: An exploration of female activewear consumption. Sport Management Review. 